\title{
COMPORTAMENTO METAL-ESCÓRIA EM MODELO FÍSICO DE UM REATOR RH: APLICAÇÃO À DESSULFURAÇÃO *
}

\author{
Johne Jesus Mol Peixoto ${ }^{1}$ \\ Weslei Viana Gabriel ${ }^{1}$ \\ Thiago Araújo Santos de Oliveira ${ }^{2}$ \\ Natália Barros Barony ${ }^{3}$ \\ Carlos Antônio da Silva ${ }^{4}$ \\ Itavahn Alves da Silva ${ }^{5}$ \\ Varadarajan Seshadri ${ }^{6}$
}

\begin{abstract}
Resumo
Utilizando um modelo físico de um reator $\mathrm{RH}$ em escala 1:7,5, simulou-se o processo de injeção de material dessulfurante na câmara de vácuo, buscando evidenciar a influência da vazão de gás e da diferença de densidade entre as fases sobre o tempo de residência e sobre o tamanho das gotas de escória arrastadas pelo metal, parâmetros essenciais para uma estimativa da taxa de dessulfuração. $O$ aumento na densidade do fluido similar ao aço resultou em considerável prolongamento no tempo de residência e diminuição do diâmetro médio das gotas de óleo arrastadas. Para a solução salina $(\mathrm{NaCl})$ como fluido de circulação, observou-se que a redução da vazão de gás aumenta o tempo de residência das partículas de dessulfurante. Tais resultados sugerem que existe uma vazão ótima de gás para alcançar maior eficiência de dessulfuração no $\mathrm{RH}$, isto é, maior tempo de residência do material dessulfurante e arraste de gotas de escória de menor diâmetro.
\end{abstract}

Palavras-chave: Desgaseificador RH; Dessulfuração; Modelamento Físico.

SLAG-METAL BEHAVIOR IN PHYSICAL MODEL OF A RH REACTOR: APLICATION TO STEEL DESULFURIZATION
Abstract
A 1:7.5 model of a $\mathrm{RH}$ degasser was employed in order to evaluate the average residence time as well as the slag droplet size distribution as a function of gas flow rate and metal slag density difference. These are parameters related to the rate of desulphurization. Increasing the density difference leads to increasing residence time and decreasing droplet size. The lower the gas flow rate the lower the circulation rate and the higher the residence time. This result suggests an optimum gas flowrate as far as desulphurization is concerned due to a combination of smaller size and higher residence time.
Keywords: Desulphurization; Physical Modelling; RH Degasser.

\footnotetext{
Eng. Metalurgista, MSc., Universidade Federal de Ouro Preto, Ouro Preto, MG, Brasil. Graduando em Engenharia Metalúrgica, Escola de Minas-UFOP, Ouro Preto, MG, Brasil. Eng. Metalurgista, Escola de Minas-UFOP, Ouro Preto, MG, Brasil.

Eng. Metalurgista, Ph.D., Professor, Departamento de Engenharia Metalúrgica e Materiais, (DEMET), EM-UFOP, Ouro Preto, MG, Brasil.
}
5 Eng. Metalurgista, DSc., Professor, DEMET, EM-UFOP, Ouro Preto, MG, Brasil.
6 Eng. Metalurgista, Dr. Ing., Professor Emérito, UFMG, Belo Horizonte, MG, Brasil. 


\section{INTRODUÇÃO}

O reator $\mathrm{RH}$ é um equipamento para refino secundário do aço líquido assistido por recirculação e desgaseificação a vácuo, visando a descarburação, remoção de nitrogênio, hidrogênio, oxigênio, enxofre, inclusões não-metálicas; adição de elementos de liga, entre outros. Devido às características do fluxo e de misturamento do aço na câmara de vácuo, o processo de refino no reator $\mathrm{RH}$ promove condições favoráveis à dessulfuração do aço, entre as quais destacam-se (Wei et al. [1]): (i) o potencial de oxigênio pode ser reduzido a níveis muito baixos; (ii) desgaseificação - remoção de hidrogênio - pode ser efetivamente conduzida durante a dessulfuração, além de se evitar o pick up de nitrogênio pelo aço; (iii) o efeito da escória de topo da panela sobre a remoção de enxofre pode ser minimizado; (iv) melhores condições cinéticas para a reação de dessulfuração. Yang et al. [2] lembram que a etapa de refino do aço no $\mathrm{RH}$ representa uma das últimas oportunidades para realizar a dessulfuração, e por este motivo, o reator $\mathrm{RH}$ tem sido aplicado na produção de aços ultrabaixo teor de enxofre.

O processo de dessulfuração do aço pelo sopro de dessulfurante pulverizado no interior da câmara de vácuo do reator $\mathrm{RH}$ foi adotado industrialmente na Wakayama Steel Works a partir de 1996 (Okano et al. [3]). O menor consumo de dessulfurante e a redução no tempo total de refino do aço são as principais vantagens deste processo frente à dessulfuração no processo convencional no forno panela. No entanto, devido à redução da vida de serviço refratário da câmara de vácuo, particularmente na perna de descida e na parte inferior do vaso do $\mathrm{RH}$, esta técnica não se tornou uma prática comum na indústria siderúrgica (Schrade et al. [4]). Por outro lado, esta é uma das poucas alternativas para produção de certos graus de aço ao silício de grão não-orientado, que contém níveis ultrabaixos de carbono e de enxofre (Schrade et al. [4]).

Zhan et al. [5] obtiveram bons resultados de dessulfuração do aço no reator $\mathrm{RH}$ através do uso de escória pré-fundida. Com um consumo de $5 \mathrm{~kg}$ de dessulfurante por tonelada de aço, foi possível reduzir, em média, o teor de enxofre de 41,9 ppm (partes por milhão) para 30 ppm, com uma taxa de dessulfuração média de $28,1 \%$. Os autores, porém ressaltaram um teor final elevado de $\mathrm{FeO}$ na escória de topo da panela. Ao modificar a escória de topo controlando seu conteúdo de $\mathrm{FeO}+\mathrm{MnO}, \mathrm{He}$ et al. [6] alcançaram uma taxa de dessulfuração de até $34,1 \%$ e o teor final de enxofre inferior a $50 \mathrm{ppm}$ em aços elétricos semi-acalmados. A escória pré-fundida foi utilizada na forma de partículas de 3 a $5 \mathrm{~mm}$, constituída de $\% \mathrm{CaO} / \% \mathrm{Al}_{2} \mathrm{O}_{3}=2,5-$ $4,0, \mathrm{CaF}_{2}<15 \%$ e $\mathrm{SiO}_{2}<5 \%$ com ponto de fusão abaixo de $1350^{\circ} \mathrm{C}$.

Costa \& Tavares [7] analisaram, via modelo matemático, a dessulfuração do aço líquido no reator $\mathrm{RH}$ por meio de escória sintética adicionada no interior da câmara de vácuo. Porém o modelo proposto previa a permanência de uma camada de escória sobrenadante ao aço na câmara de vácuo, desprezando o arraste desta escória para a panela. De modo a descrever quantitativamente a reação de dessulfuração do aço no interior do reator $\mathrm{RH}$, o tamanho de partículas (ou gotas de escória) e o tempo de residência deste material no seio do aço líquido precisam ser conhecidos (Wei et al. [1]). 
Para analisar as interações entre metal e escória em processos metalúrgicos recorre-se frequentemente a técnicas de modelamento físico. Neste sentido, o sistema água/óleo apresenta uma deficiência quanto à diferença de densidade. Para aumentar a diferença de densidade entre os materiais similares a aço e escória, pode-se utilizar solução aquosa - cloreto de zinco (Lin e Guthrie [8] e Arruda [9]) ou cloreto de sódio (Savolainen et al. [10]). Em um trabalho anterior, Peixoto et al. [11] utilizaram um sistema de medição indireta da taxa de circulação a partir de uma ponte de strain gages, investigando o efeito da vazão de gás e imersão das pernas sobre a taxa de circulação no reator $\mathrm{RH}$. Os resultados obtidos para água e solução aquosa de $\mathrm{ZnCl}_{2}$ foram coerentes e permitem a utilização destas soluções salinas e óleos de silicone para avaliar o comportamento da escória adicionada na câmara de vácuo do RH. Posteriormente, Peixoto et al. [12] observaram que mesmo em vazões mais baixas de gás, uma camada de $10 \mathrm{~mm}$ de óleo sobrenadante na câmara de vácuo era completamente arrastada para a panela em até $14 \mathrm{~s}$ quando se utiliza água e 180 s com solução aquosa de $\mathrm{ZnCl}_{2}$ (densidade $1,22 \mathrm{~g} / \mathrm{cm}^{3}$ ).

O processo de injeção de material dessulfurante na câmara de vácuo foi simulado em um modelo físico de um reator $\mathrm{RH}$, buscando evidenciar a influência da vazão de gás e da diferença de densidade entre as fases sobre o tempo de residência do material e o tamanho das gotas de óleo que são arrastadas pelo fluxo de líquido no interior do modelo.

\section{MATERIAIS E MÉTODOS}

Os testes foram realizados em um modelo físico do sistema $\mathrm{RH}$ construído em acrílico, obedecendo a um fator de escala 1:7,5, cujas dimensões principais são apresentadas na Figura 1. Dados geométricos e operacionais do modelo e do reator industrial (protótipo) em que este modelo se baseia, assim como informações sobre os critérios de similaridade adotados podem ser encontrados em Peixoto et al. [11].

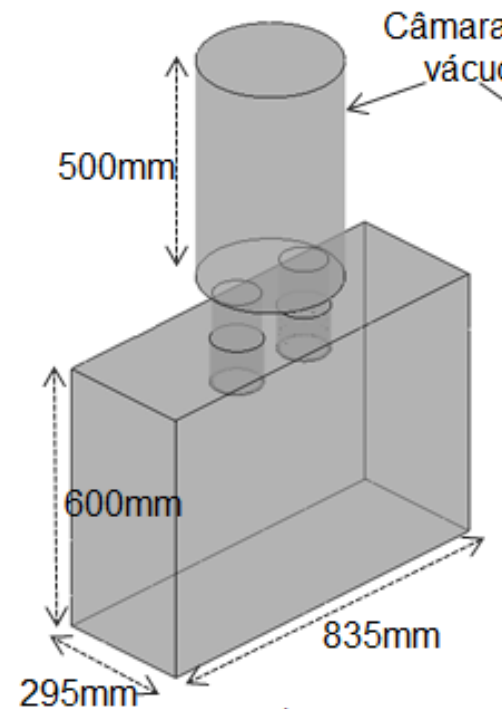

a)



Perna de subida

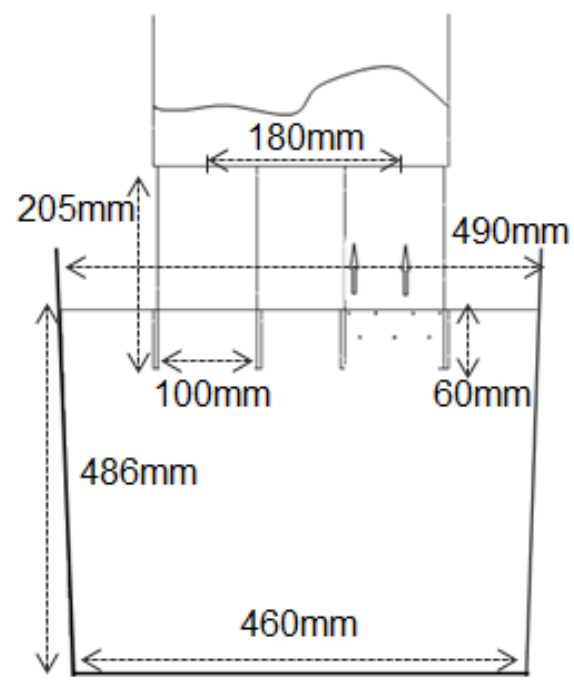

b)

Figura 1. Representação esquemática com as principais dimensões do modelo em acrílico do reator $\mathrm{RH}$ : a) vaso inferior retangular (caixa); b) vaso inferior cilíndrico (panela).

\subsection{Determinação da Taxa de Circulação - Método de Ponte de Strain Gages}


Para determinação da taxa de circulação no modelo de $\mathrm{RH}$, foi utilizado um sistema de medição indireta a partir de uma ponte de strain gages. Conforme mostrado no esquema da Figura 2.a, uma esfera de massa e raio conhecidos é dependurada na extremidade de uma lâmina flexível. Dois Strain Gages são colados na face superior da lâmina e outros dois na face inferior, interconectados de forma a compor uma ponte completa de Wheatstone, cujo sinal elétrico depende da deformação. A esfera é posicionada na perna de descida, estando portanto sujeita à interação com o fluido que retorna à panela. Desta forma, a esfera está sujeita a esforços correspondentes ao peso, empuxo e força de arraste proporcionada pelo fluido. Maior a vazão de fluido, maior a força de arraste, maior a deformação da lâmina e maior o sinal gerado pela ponte. Portanto o sinal da ponte pode ser utilizado para se estimar a vazão (taxa de circulação). Mais detalhes podem ser encontrados em Peixoto et al. [11].

\subsection{Injeção de material na câmara de vácuo}

Foram utilizadas partículas de polipropileno ( $\rho=889 \mathrm{~kg} / \mathrm{m}^{3}$, diâmetro médio $3,5 \mathrm{~mm}$ ), para simular a injeção do dessulfurante no estado sólido (partículas) na câmara de vácuo do modelo do reator $\mathrm{RH}$ - utilizando vaso inferior cilíndrico, conforme Figura 1.b. Como representado na Figura 2.b, $250 \mathrm{~g}$ de partículas foram injetados na câmara de vácuo a uma altura $\mathrm{H}=20 \mathrm{~cm}$ acima da superfície do líquido na câmara de vácuo. Uma câmera de alta definição foi posicionada frontalmente a câmara de vácuo e outra frontalmente a panela (seção longitudinal) de modo a capturar o movimento do material arrastado pelo fluxo. As filmagens são então utilizadas para avaliar o trajeto do material arrastado entre a câmara de vácuo e a superfície da panela, estimar o tempo que o material leva para ser arrastado da câmara de vácuo e o tempo no qual o material permanece disperso no interior do fluido de circulação. Foram realizados 2 testes para cada vazão de gás $(60 \mathrm{~L} / \mathrm{min}, 70 \mathrm{~L} / \mathrm{min}, 80 \mathrm{~L} / \mathrm{min}$ e $90 \mathrm{~L} / \mathrm{min}$ e $100 \mathrm{~L} / \mathrm{min}$ ) e a imersão das pernas foi mantida igual a $60 \mathrm{~mm}$.

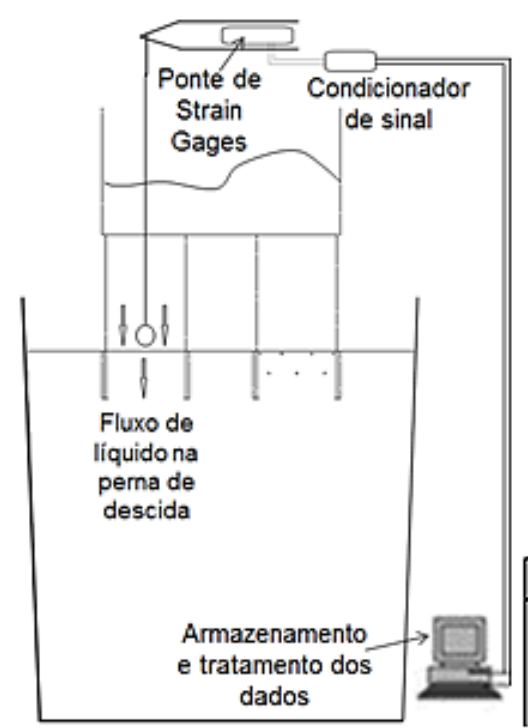

a)

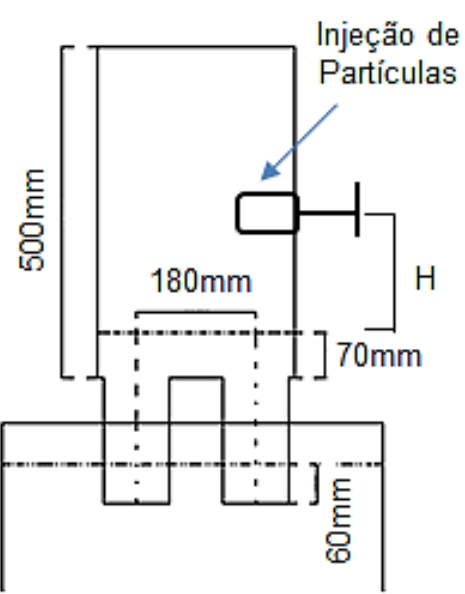

b)

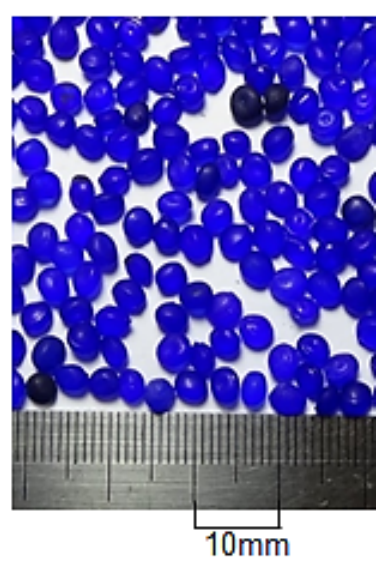

c)

Figura 2. (a) Diagrama esquemático do sistema de medição de taxa de circulação pelo método da

Ponte de Strain Gages; (b) representação esquemática da posição para injeção de partículas na câmara de vácuo do modelo do reator $\mathrm{RH}$; (c) partículas de polipropileno $\left(\rho=889 \mathrm{~kg} / \mathrm{m}^{3}\right)$, com diâmetro médio de $3,5 \mathrm{~mm}$. 


\subsection{Medição de diâmetro de gota de óleo}

Visando avaliar o arraste de dessulfurante líquido da câmara de vácuo para a panela, $400 \mathrm{~mL}$ de óleo de silicone (viscosidade $500 \mathrm{cSt}$ ) foram injetados na câmara de vácuo, como esquematizado na Figura 2.b, a uma altura $\mathrm{H}=10 \mathrm{~cm}$. O óleo foi injetado através de um tubo de $20 \mathrm{~mm}$ e durante aproximadamente $8 \mathrm{~s}$. Para evitar distorções nas imagens e permitir uma estimativa confiável do tamanho das gotas de óleo arrastadas pelo fluxo, utilizou-se o vaso inferior no formato retangular (Figura 1.a). Uma câmera de alta definição e de alta velocidade AOS S-PRI foi posicionada logo abaixo da saída da perna de descida de modo a capturar imagens das gotas de óleo arrastadas. Foi utilizada a velocidade de 300 quadros/segundo. A Tabela 1 apresenta as propriedades dos fluidos utilizados nestes testes. Para cada condição experimental (tipo de fluido e vazão de gás) foram realizadas 2 filmagens e de cada uma destas selecionou-se 12 imagens para avaliação de quantidade, da morfologia e do tamanho (diâmetro) das gotículas de óleo formadas.

Tabela 1. Valores da viscosidade e densidade de materiais utilizados no modelamento da interação metal/escória.

\begin{tabular}{|c|c|c|c|c|}
\hline Material & $\begin{array}{c}\text { Densidade } \\
\left(\mathrm{kg} / \mathrm{m}^{3}\right)\end{array}$ & $\begin{array}{c}\text { Viscosidade } \\
\text { cSt }^{\text {(a) }}\end{array}$ & $\begin{array}{c}\sigma(\mathrm{mN} / \mathrm{m}) \\
\mathrm{ar}\end{array}$ & $\begin{array}{c}\sigma(\mathrm{mN} / \mathrm{m}) \\
\text { óleo }\end{array}$ \\
\hline Água & 1000 & 1 & 72 & 40,9 \\
\hline Cloreto de Sódio (NaCl) & 1170 & $1,33^{(b)}$ & 59,2 & 40,1 \\
\hline Óleo de Silicone & 950 & 500 & 39,4 & - \\
\hline
\end{tabular}

Para avaliar o tamanho das gotas de óleo que são arrastadas para a panela, as imagens capturadas abaixo da perna de descida foram tratadas utilizando-se 0 programa livre ImageJ. Através de uma prévia calibração, o programa permite estimar simultaneamente a área de várias partículas numa mesma imagem. A calibração consiste em fornecer ao programa uma distância conhecida de modo a determinar a relação entre $\mathrm{mm}$ /pixels na imagem. As imagens passam por tratamento prévio para melhorar o contraste, permitindo a identificação dos contornos das gotas. A Figura 3 exemplifica algumas imagens obtidas entre as principais etapas de medição. Utilizando o MS Excel e assumindo que as gotas são esféricas, calculou-se o diâmetro de cada gota. $O$ total de gotas mensuradas foi entre 230 (água) e $284(\mathrm{NaCl})$ gotas por teste. Destes dados, determina-se a distribuição de tamanhos, o diâmetro médio e o desvio padrão. O diâmetro médio de Sauter ( $\mathrm{d}_{32}$, dado pela Equação (1), conforme Zaidi \& Sohn [13]) também foi utilizado para evidenciar a influência da vazão de gás e da diferença de densidade entre os fluidos sobre o tamanho das gotas arrastadas. O diâmetro de Sauter é usualmente utilizado pois é facilmente correlacionado com a área interfacial por unidade de volume $(A)$ de acordo com a Equação (2) (Zaidi \& Sohn [13]):

$$
\begin{array}{r}
d_{32}=\frac{\sum n_{i} d_{i}^{3}}{\sum n_{i} d_{i}^{2}} \\
A=\frac{6 \emptyset}{d_{32}}
\end{array}
$$

Onde $n_{i}$ é o número de gotas de diâmetro di; $\emptyset$ é a fração volumétrica de gotas dispersas no fluido principal. 


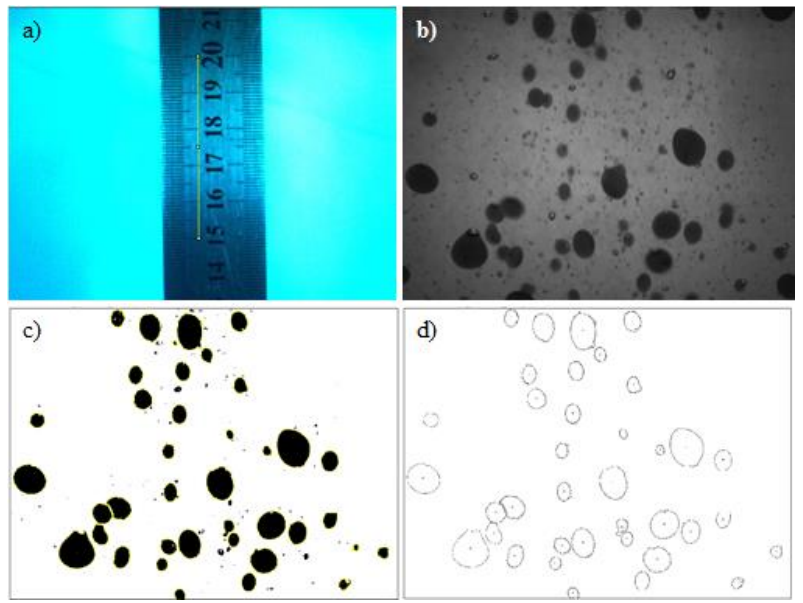

Figura 1. a) Exemplo de escala para calibração do programa ImageJ; b) imagem original de gotas logo abaixo da saída da perna de descida; c) imagem das gotas após tratamento de remoção de plano de fundo e transformação via limiarização; d) contornos das gotas que foram mensuradas pelo programa.

\section{RESULTADOS E DISCUSSÃO}

\subsection{Taxa de circulação}

$\mathrm{Na}$ Figura 4 tem-se uma comparação entre os valores de taxa de circulação obtidos pelo método da ponte de Strain Gages utilizando água e solução aquosa de $\mathrm{NaCl}$ para o vaso inferior nos formatos retangular (caixa) e cilíndrico (panela). Como era esperado, a influência do formato do vaso inferior sobre os valores de taxa de circulação foi desprezível. Desta forma, o vaso retangular pode ser utilizado para avaliar o tamanho das gotas de óleo arrastadas da câmara de vácuo, sem prejuízo à similaridade, pois as imagens são capturadas logo na saída da perna de descida. Nota-se também que o aumento na densidade do fluido de circulação resultou em aumento da taxa de circulação, em cerca de $22 \%$ quando se utiliza a panela e $30 \%$ para a caixa retangular. Como este aumento é próximo ao aumento na densidade (17\%), a velocidade média do fluido na perna de descida sofreu pequena alteração.
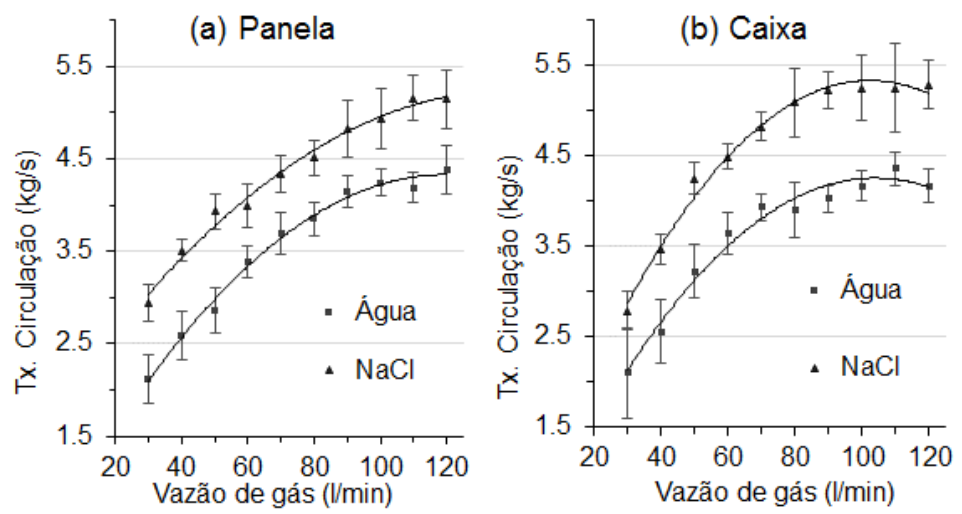

Figura 4. Comparação dos valores da taxa de circulação utilizando água, solução aquosa de $\mathrm{NaCl}$ e de $\mathrm{ZnCl}$, para o vaso inferior: (a) panela; (b) caixa.

Kuwabara et al. [14] propuseram uma relação empírica para determinação da taxa de circulação $\left(Q_{c}\right)$ no reator $R H$, Equação (3): 


$$
Q c \propto Q_{g}^{\frac{1}{3}} D_{l}^{\frac{4}{3}}\left[\ln \left(\frac{P_{b}}{P_{C V}}\right)\right]^{\frac{1}{3}}
$$

Onde $Q_{g}$ : vazão de gás $\left(\mathrm{Nm}^{3} / \mathrm{s}\right)$; $\mathrm{D}_{\mathrm{l}}$ : Diâmetro da perna $(\mathrm{m})$; $\mathrm{P}_{\mathrm{b}}$ e $\mathrm{P}_{\mathrm{cv}}$, pressão na ponta dos bicos de injeção e na câmara de vácuo, respectivamente.

A relação entre taxa de circulação e $Q_{g}{ }^{1 / 3} D_{\text {leg }}{ }^{4 / 3}$ é apresentada na Figura 5. $O$ parâmetro $R^{2}$ foi maior que 0,85 para os resultados obtidos utilizando o vaso inferior no formato cilíndrico. Além disso, para a água, os coeficientes angulares das duas curvas foram muito próximos, indicando a equivalência entre os valores de taxa de circulação utilizando 0 vaso inferior de diferentes formatos. Os coeficientes angulares das curvas utilizando solução salina como fluido de circulação também foram próximos, mas são maiores que para a água. Isto pode ser explicado devido a maior densidade das soluções e consequentemente maior pressão na saída dos bicos para uma mesma vazão de gás e menor pressão na câmara de vácuo, ou seja, maior razão $P_{b} / P_{C V}$.
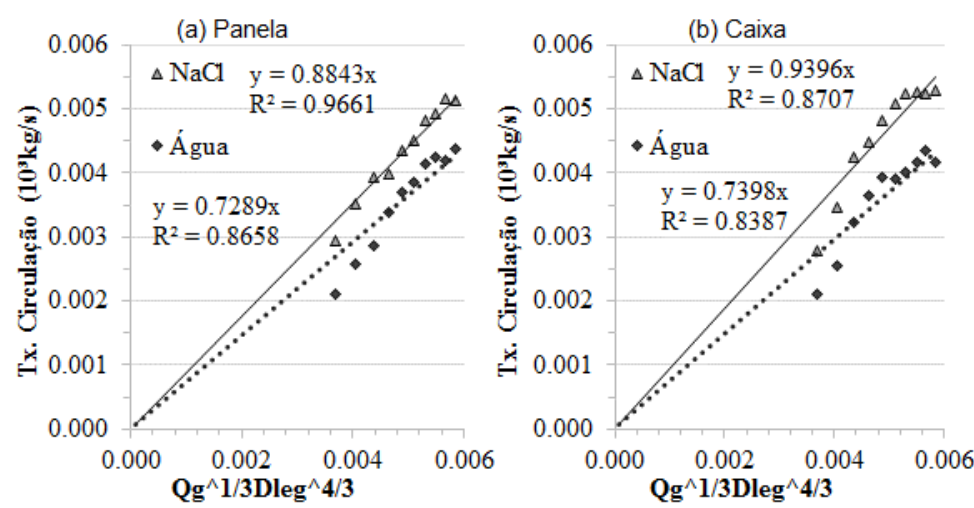

Figura 5. Relação entre valores de taxa de circulação obtidos e $Q_{g}{ }^{1 / 3} D_{\text {leg }}{ }^{4 / 3}$ para o vaso inferior: (a) panela; (b) caixa.

\subsection{Injeção de material na câmara de vácuo}

A sequência de imagens na Figura 6 resume o comportamento das partículas no interior da câmara de vácuo, destacando a influência da diferença de densidade sobre arraste das partículas. Nota-se que ao atingir a superfície do fluido com velocidade de aproximadamente $1,9 \mathrm{~m} / \mathrm{s}$, resultante da queda livre a $20 \mathrm{~cm}$ acima do nível de líquido, as partículas imergem no fluido, e na água grande parte é arrastada para a panela, enquanto na solução de $\mathrm{NaCl}$, uma considerável fração das partículas acumula-se na superfície do fluido sobre a perna de descida. Devido à turbulência no interior da câmara de vácuo, a formação de pequenos vórtices sobre a perna de descida é responsável pelo arraste das partículas na superfície do líquido para o interior da panela. A frequência de ocorrência destes redemoinhos e sua capacidade de arrastar partículas aumentam para maiores vazões de gás, e consequentemente o tempo de residência das partículas na câmara de vácuo se reduz com o aumento da vazão de gás. Ressalta-se ainda que após 10s a quantidade de partículas dispersas na água é muito inferior à quantidade dispersa na solução salina.

Na Figura 7, observa-se o comportamento das partículas no interior da panela (vaso cilíndrico). Nota-se que as partículas são arrastadas até próximo ao fundo da panela, 
e pela ação do empuxo rapidamente flotam para a superfície livre da panela. Para a solução salina, o movimento das partículas é regido principalmente pelo empuxo, e as partículas ficam restritas à região abaixo e ao redor da perna de descida. Enquanto para a água, devido à redução na diferença de densidade, uma quantidade considerável de partículas acompanha o fluxo de líquido e alcança a perna de subida, resultando em uma recirculação de partículas entre a panela e a câmara de vácuo. O tempo médio para arraste das partículas da câmara de vácuo e o tempo médio de permanência das partículas na panela são apresentados na Figura 8. Utilizando água, a diferença entre o tempo de arraste da câmara de vácuo e de permanência da panela é devido à recirculação de partículas. Frente à elevada relação entre densidade do aço e da escória dessulfurante, é improvável que este fenômeno de recirculação ocorra no sistema real. Para a solução salina, nota-se uma considerável redução no tempo de residência das partículas para as duas vazões (de gás) mais altas, e o tempo necessário para que todas as partículas alcancem a superfície livre da panela varia entre 19 e 27s.

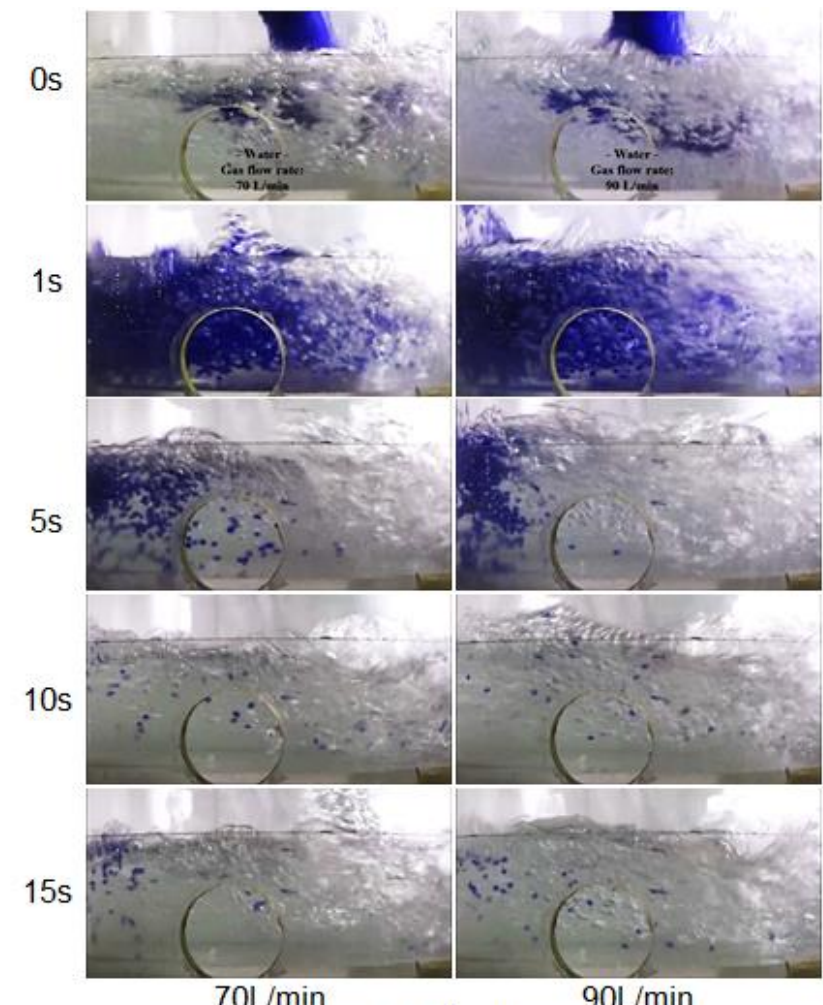

(a) Água

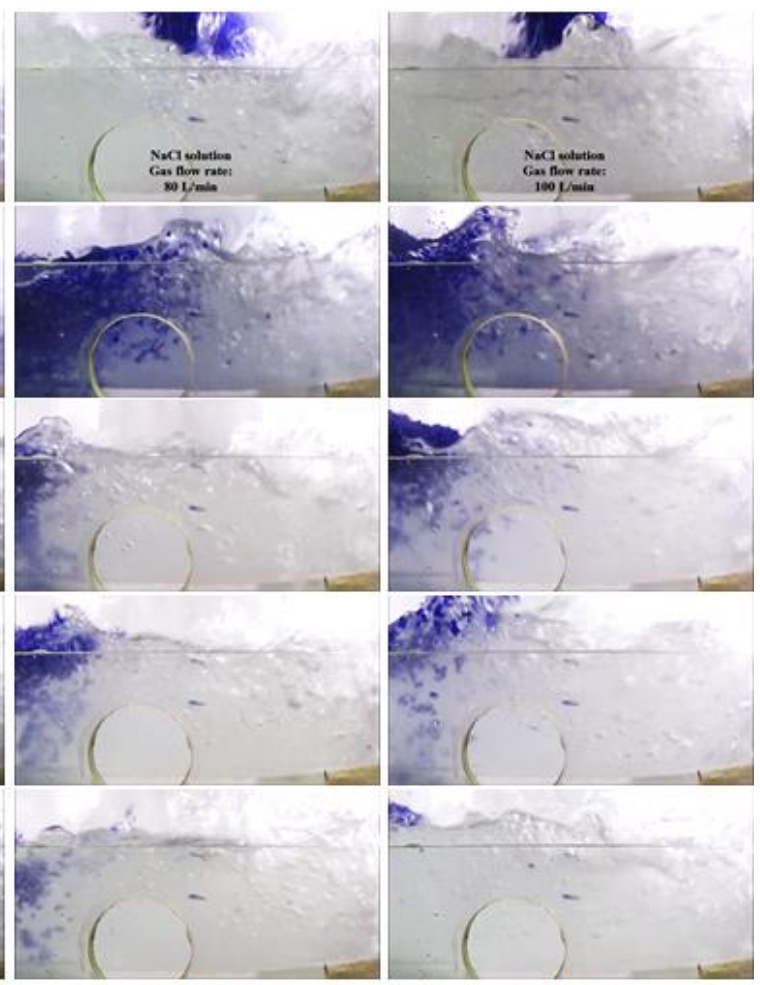

(b) $\mathrm{NaCl}$

$100 \mathrm{~L} / \mathrm{min}$

Figura 6. Dispersão das partículas de polipropileno no interior da câmara de vácuo do modelo do reator RH m função do tempo para: (a) água; (b) solução salina $\mathrm{NaCl}$.

Como destacado por Yang et al. [2], o melhor caminho para se elevar a taxa de dessulfuração no $\mathrm{RH}$ é aumentando o tempo de residência do dessulfurante no interior do aço líquido. Estes autores obtiveram bons resultados de dessulfuração ao reduzir a vazão de gás de $60 \mathrm{~m}^{3} / \mathrm{h}$ para $50 \mathrm{~m}^{3} / \mathrm{h}$ num reator $\mathrm{RH}$ de $100 \mathrm{t}$ de capacidade, retornando ao valor normal de trabalho 5 minutos após a injeção do dessulfurante. Vazões de gás mais baixas implicam em maior queda de temperatura e redução na taxa de circulação, o que pode reduzir a eficiência de dessulfuração. Neste sentido, a partir da Figura 8, o maior tempo de residência das partículas aliado a maior taxa de circulação de líquido é obtido para a vazão de gás igual a $80 \mathrm{~L} / \mathrm{min}$, o que corresponde à vazão de $100 \mathrm{Nm}^{3} / \mathrm{h}$ no reator industrial (capacidade $315 \mathrm{t}$ de aço). 


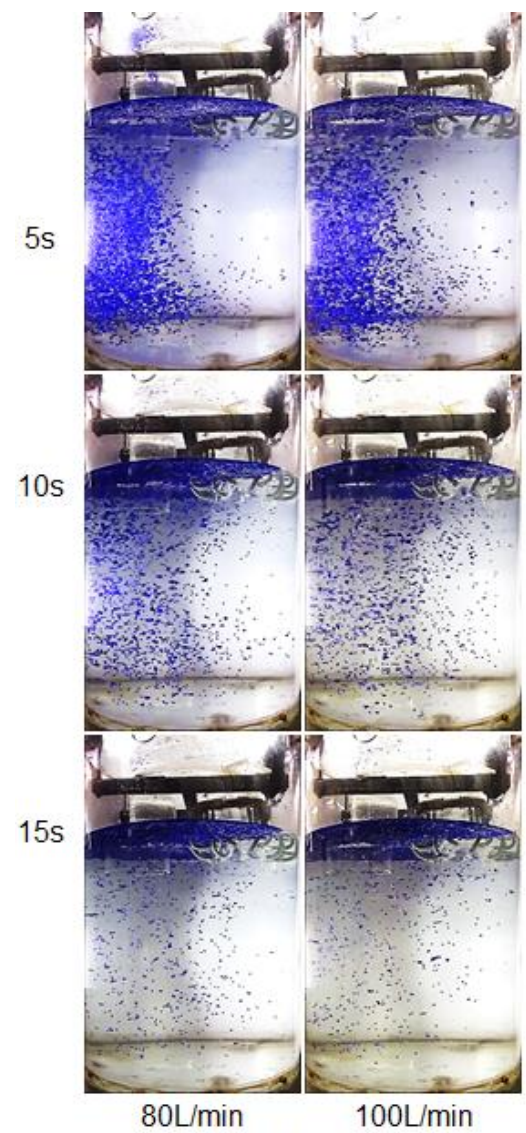

(a) Água

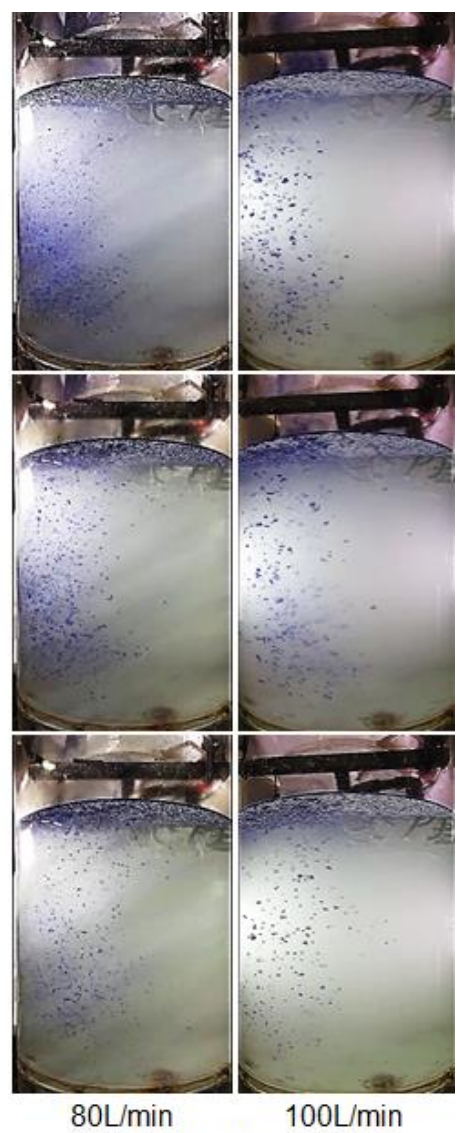

(b) $\mathrm{NaCl}$

Figura 7. Dispersão das partículas de polipropileno no interior da panela do modelo físico do reator $\mathrm{RH}$ em função do tempo para: (a) água; (b) solução salina $\mathrm{NaCl}$.



Figura 8. Tempo de residência das partículas no interior do líquido - CV: câmara de vácuo.

\subsection{Diâmetro das gotas de óleo arrastadas pelo fluxo}

As imagens capturadas logo abaixo da saída da perna de descida foram utilizadas para avaliar o tamanho das gotas de óleo arrastadas para o vaso inferior. A Figura 9 apresenta algumas imagens para diferentes vazões. Utilizando água, observam-se gotas maiores e mais deformadas com o aumento de vazão de gás. Para a solução salina, nota-se uma maior quantidade de gotas, que são menores e mais uniformes. O gráfico da Figura 10 elucida estes aspectos. Nota-se ainda que os diâmetros máximos das gotas arrastadas na água são muito superiores àqueles na solução salina. Apesar da maior dispersão no tamanho das gotas de óleo na água quando comparada á solução salina, os valores médios de diâmetro são muito próximos. $O$ diâmetro de Sauter $\left(\mathrm{d}_{32}\right)$ médio das gotas é apresentado na Tabela 2. Desta forma, é possível notar a influência da diferença de densidade sobre o tamanho das gotas de 
óleo arrastadas. Para a solução salina, observa-se uma redução no valor de $d_{32}$ com o aumento da vazão de gás. Deve-se ressaltar que a vazão ótima de gás para dessulfuração deve fornecer menor diâmetro médio (maior área superficial), e maior tempo de residência do material no interior do líquido, parâmetros essenciais para elevar a cinética de dessulfuração. Assim, a escolha da vazão de gás durante a adição do material dessulfurante deve considerar um equilíbrio entre tais parâmetros.

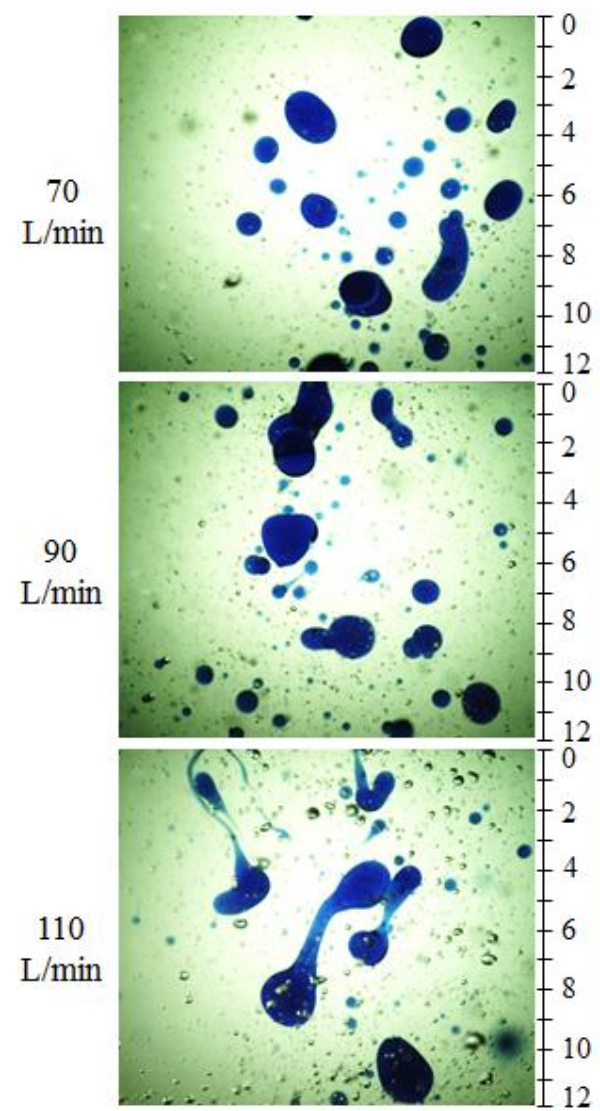

(a) Água $(\mathrm{cm})$

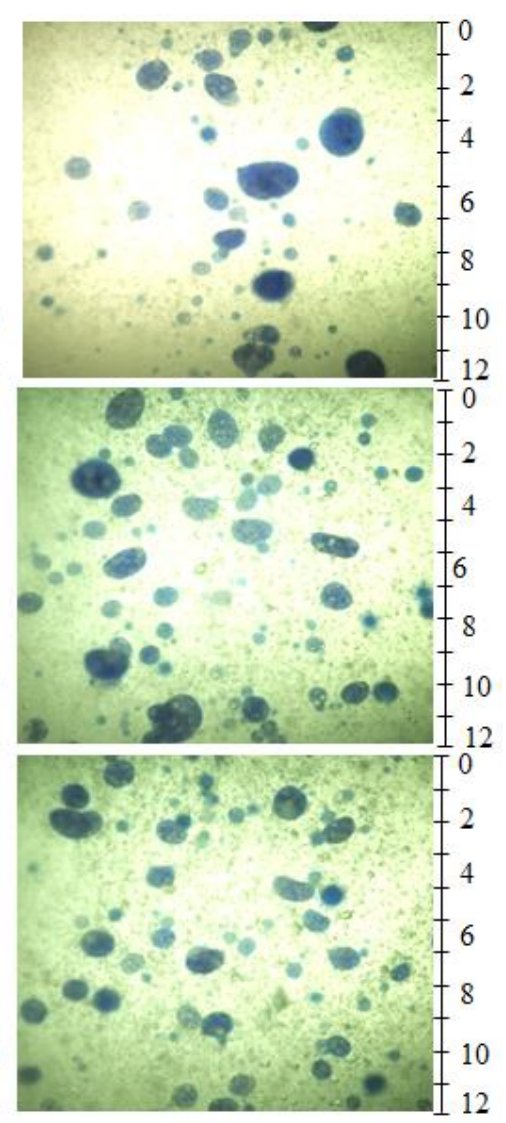

(b) $\mathrm{NaCl}$ $(\mathrm{cm})$

Figura 9. Morfologia das gotas de óleo logo abaixo da perna de descida, 2 segundos após a passagem da primeira gota de óleo. Fluido de circulação: (a) água; (b) $\mathrm{NaCl}$.

(a) Água



(b) $\mathrm{NaCl}$

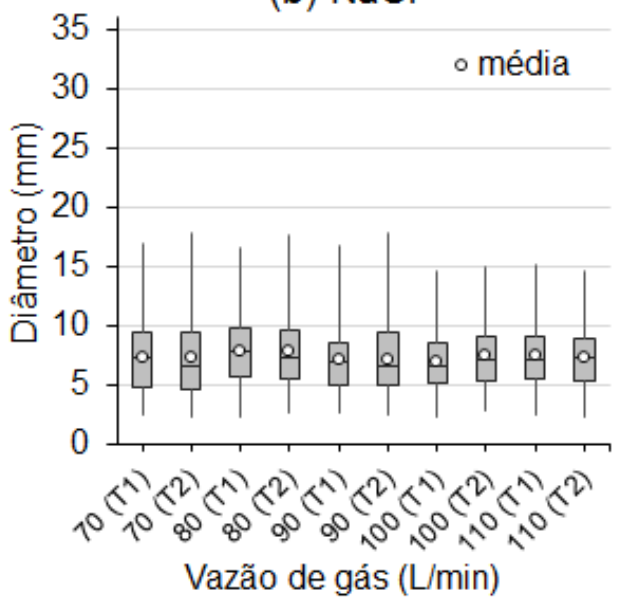

Figura 10. Diagrama de caixa e valor médio do diâmetro das gotas de óleo arrastadas da câmara de vácuo para fluido de circulação: (a) água; (b) solução aquosa de $\mathrm{NaCl}$. ${ }^{*} 11$ - teste 1 e T2 - teste 2. 
Tabela 2. Diâmetro médio de Sauter das gotas de óleo arrastadas da câmara de vácuo para a panela

\begin{tabular}{|c|c|c|c|c|c|c|}
\hline \multirow{2}{*}{$\begin{array}{c}\text { Diâmetro } \\
\text { de Sauter }\end{array}$} & Vazão (L/min) & $\mathbf{7 0}$ & $\mathbf{8 0}$ & $\mathbf{9 0}$ & $\mathbf{1 0 0}$ & $\mathbf{1 1 0}$ \\
\cline { 2 - 7 } $\mathrm{d}_{32}(\mathrm{~mm})$ & $\mathrm{NaCl}$ & 9,7 & 9,8 & 9,1 & 8,9 & 9,0 \\
\cline { 2 - 7 } & água & 14,7 & 15,6 & 17,2 & 16,0 & 15,7 \\
\hline
\end{tabular}

Savolainen et al. [10] também observaram considerável influência da diferença de densidade entre os fluidos sobre o diâmetro médio das gotas de óleo formadas em seus testes. Este efeito foi explicado pela força de empuxo: mais alta a diferença de densidade então maior é a força de empuxo agindo sobre as gotas, o que evita a formação de gotas maiores.

A partir de cálculos teóricos sobre a velocidade do aço no interior da perna de descida e das propriedades físicas do aço e da escória dessulfurante, Silva et al. [15] encontraram um diâmetro máximo de partícula arrastada igual a $40 \mathrm{~mm}$, e consideraram um diâmetro médio igual a $1 / 5$ deste valor, ou seja, $8 \mathrm{~mm}$ para estimativa da taxa de dessulfuração a partir de dados simulação matemática. A taxa de dessulfuração calculada foi $50 \%$, superior ao que foi obtido industrialmente (média de 35\%). Considerando-se o diâmetro médio obtido nestes experimentos, da ordem de $9 \mathrm{~mm}$ (obtido via modelo físico para a solução salina), o valor de taxa de dessulfuração calculado seria da ordem de $40 \%$, mais próximo do valor observado industrialmente.

Diante dos resultados expostos anteriormente, destaca-se a importância de se utilizar fluidos com maior diferença de densidade para simular o comportamento escória/aço. Neste sentido, os resultados obtidos quando se utiliza solução aquosa de $\mathrm{NaCl}$ sugerem que a vazão de gás igual a $80 \mathrm{~L} / \mathrm{min}\left(100 \mathrm{Nm}^{3} / \mathrm{min}\right.$ no reator industrial) aumenta a eficiência de dessulfuração, isto é, maior tempo de residência do material dessulfurante e arraste de gotas de escória de menor diâmetro (maior área superficial para reação de dessulfuração).

\section{CONCLUSÃO}

Os principais resultados obtidos a partir do modelamento físico do reator $\mathrm{RH}$, utilizando água e solução salina $(\mathrm{NaCl})$ como fluido de circulação, são:

- O aumento na densidade do fluido de circulação elevou a taxa de circulação de modo proporcional ao aumento na densidade;

- O formato do vaso inferior teve influência desprezível sobre os valores de taxa de circulação, o que dá suporte à utilização do vaso retangular para avaliar o tamanho das gotas formadas pela injeção de óleo na câmara de vácuo do modelo físico do reator $\mathrm{RH}$;

- Reduzindo adequadamente a vazão de gás pode-se prologar o tempo de residência das partículas de dessulfurante, aumentando assim a taxa de dessulfuração;

- A maior diferença entre as densidades do óleo e do fluido de circulação resultou em menor diâmetro médio das gotas arrastadas: diâmetro de Sauter $\left(\mathrm{d}_{32}\right)$ médio foi $16 \mathrm{~mm}$ (água) e $9 \mathrm{~mm}(\mathrm{NaCl})$.

\section{Agradecimentos}

Ao CNPq, à CAPES, à Fundação Gorceix e à FAPEMIG pelo apoio. 


\section{REFERÊNCIAS}

1 Wei JH, Zhu SJ, Yu NW. Kinetic model of desulphurisation by powder injection and blowing in RH refining of molten steel. Iron. and Steelmaking. 2000;27(2): 129-137.

2 Yang $\mathrm{H}$, Yang $\mathrm{S}$, $\mathrm{Li} \mathrm{J}$, Zhang J. A mathematical model to characterize $\mathrm{RH}$ desulfurization process. Journal of Iron and Steel Research Int. 2014; 21(11): 995-1001.

3 Okano H, Tajiri Y, Satoh M, Fukagawa S, Shinme K. Development of technology for producing ultra low sulphur steel by $\mathrm{RH}$ top blowing method. The Sumitomo Search. 1997; 59: 91-95.

4 Schrade C, Nicolai H, Zulhan Z. Desulfurization of molten steel in RH-degasser by powder blowing to produce silicon steel - Operational Results Maanshan ISCO. In: METEC. $2^{\circ}$ ESTAD; 2015; Düsseldorf, Alemanha. Düsseldorf: METEC; 2015. p. 1-5.

5 Zhan D P, Jiang Z H, Wang W Z. Development of deep desulfurization technology with premelted slag during RH-KTB refining. Dev. Chem. Eng. Mineral Process. 2006; 14(3/4): 375-384.

6 He S, Zhang G, Wang Q. Desulphurisation process in $\mathrm{RH}$ degasser for soft-killed ultralow- carbon electrical steels. ISIJ Int. 2012; 52 (6): 977-983.

7 Costa L T, Tavares R P. Dessulfuração do aço em desgaseificador $\mathrm{RH}$ por meio de modelo matemático. In: Associação Brasileira de Metalurgia, Materiais e Mineração. Anais do 46ํㅡㄴ Seminário de Aciaria - Internacional; 2015; Rio de Janeiro, Brasil. São Paulo: ABM; 2015. p.552-561.

8 Lin Z, Guthrie R I L. Modeling of metallurgical emulsions. Metallurgical and Materials Transactions B. 1994; 25 (B): 855-864.

9 Arruda J D. Análise Via Modelagem Física e Matemática da Turbulência na Interface Metal/Escória na Região do Menisco em um Molde de Lingotamento Contínuo de Placas [dissertação de mestrado]. Ouro Preto: REDEMAT; 2015.

10 Savolanein J, Fabritius T, Mattila O. Effect of Fluid Physical Properties on the Emulsification. ISIJ International. 2009; 49(1): 29-36.

11 Peixoto J J M, Barony N B, Gabriel W V, Silva C A, Silva I A, Seshadri V. Taxa de circulação e previsão do comportamento metal/escória em modelo físico de um reator $\mathrm{RH}$. In: Associação Brasileira de Metalurgia, Materiais e Mineração. Anais do 47ํㅜㅇ Seminário de Aciaria - Int.; Rio de Janeiro, Brasil. São Paulo: ABM; 2016. p.639-648.

12 Peixoto J J M, Barony N B, Souza H H S, Gabriel W V, Silva C A, Silva I A, Seshadri V. Assessment of slag entrainment in a $\mathrm{RH}$ degasser through physical modelling using circulating fluids of different densities/oil systems for simulating steel melt/slag. In: 8th International Symposium on High-Temperature Metallurgical Processing. Pittsburgh: The Minerals, Metals \& Materials Society (TMS); 2017. p. 121-131.

13 Zaidi A, Sohn HY. Measurement and Correlation of Drop-Size Distribution in LiquidLiquid Emulsions Formed by High-Velocity Botton Gas Injection. ISIJ Int. 1995;35(3):234-241.

14 Kuwabara T, Umezawa K, Mori K, Watanabe H. Investigation of decarburization behavior in $\mathrm{RH}$-Reactor an its operation improvement. Trans. ISIJ. 1981; 28: 305-314.

15 Silva T C, Rodrigues E F, Soares C, Silva C A, Silva I A. Simulação numérica do fluxo recirculatório em um reator $\mathrm{RH}$ : Aplicação à dessulfuração. In: Associação Brasileira de Metalurgia, Materiais e Mineração. 46을 Seminário Internacional de Aciaria; Rio de Janeiro, Brasil. São Paulo: ABM; 2015. 1-10. 